\title{
Prevalence and associated factors of herbal medicine use among pregnant women on antenatal care follow-up at University of Gondar referral and teaching hospital, Ethiopia: a cross-sectional study
}

\author{
Abebe Basazn Mekuria ${ }^{1,4^{*}}$, Daniel Asfaw Erku², Begashaw Melaku Gebresillassie², Eshetie Melese Birru',
} Balem Tizazu ${ }^{3}$ and Alima Ahmedin ${ }^{2}$

\begin{abstract}
Background: Improving maternal and child health is one of the public health priorities in several African countries including Ethiopia. However, research on herbal medicine use during pregnancy is scarce in Ethiopia. The present study aimed at assessing the prevalence and correlates of herbal medicine use among pregnant women on antenatal care (ANC) follow-up at Gondar university referral hospital, Ethiopia

Methods: An institutional-based cross sectional study was conducted on 364 pregnant women attending ANC clinic from March to May 2016 at University of Gondar referral and teaching hospital, northwest Ethiopia. Data on socio-demography, pregnancy related information as well as herbal medicine use was collected through an interviewer-administered questionnaire. Descriptive statistics, univariate and multivariate logistic regression analysis were performed to determine prevalence and associated factors of herbal medicine use.

Results: From 364 respondents, 48.6\% used herbal medicine during current pregnancy. ginger (40.7\%) and garlic (19\%) were the two most commonly used herbs in pregnancy. Common cold (66\%) and inflammation (31.6\%) were the most common reasons for herbal use. Majority of herbal medicine users (89.8\%) had not consulted their doctors about their herbal medicine use. Rural residency (Adjusted odds ratio (AOR): 3.15, Confidence interval (CI): 1.17-6.14), illiteracy (AOR: 4.05, Cl: 2.47-6.62) and average monthly income less than 100 USD (AOR: 3.08Cl: $1.221-7.77)$ were found to be strong predictors of herbal medicine use.
\end{abstract}

Conclusions: The use of herbal medicine during pregnancy is a common practice and associated with residency, level of education and average monthly income. From the stand point of high prevalence and low disclosure rate, the health care providers should often consult pregnant women regarding herbal medicine use.

Keywords: Pregnant women, Herbal medicine, Maternal health, Ethiopia

\footnotetext{
* Correspondence: abeyohannes21@gmail.com

'Department of Pharmacology, College of Medicine and Health Sciences, University of Gondar, Chechela Street, Lideta Subcity Kebele 16, Gondar, Ethiopia

${ }^{4}$ Department of Pharmacology, School of Pharmacy, University of Gondar,

P.O. Box: 196, Gondar, Ethiopia

Full list of author information is available at the end of the article
} 


\section{Background}

Traditional medicine, according to World Health Organization (WHO), is defined as "health practices, approaches, knowledge and beliefs incorporating plant, animal and mineral based medicines, spiritual therapies, manual techniques and exercises, applied singularly or in combination to treat, diagnose and prevent illnesses and maintain well-being" [1]. Among the traditional medicine practices, the use of herbal medicines which is defined as plant-derived preparations claimed to have therapeutic benefits, is the most popular and used by the general population as well as pregnant women around the globe [2-4].

Pregnant women use herbal medicines for different purposes including pregnancy related ailments such as nausea and vomiting, enhancing labor [5] or pregnancy unrelated purposes and ailments such as cold, respiratory illnesses and skin problems as well as nutritional benefit [6]. Furthermore, pregnant women use herbal medicines due to its easy accessibility, assumed better efficacy compared to the modern medicine, traditional and cultural belief in herbal medicines to cure illnesses and comparatively low cost of herbal medicines [7, 8]. The most popular herbal remedies used by pregnant women in the world include ginger (Zingiber officinale), garlic (Allium sativum), green tea (Camellia sinensis), peppermint (Mentha piperita) and fenugreek (Trigonella foenum-graecum,) [9]. Studies conducted in Australia and Kenya have reported that factors associated with increased use of herbal medicines among pregnant women includes being older and married, low economic status, being less educated and severity of nausea and vomiting $[10,11]$. Despite the increased consumption of herbal medicines among pregnant women all over the globe, majority of them are unaware of the potential side effects and a potential teratogenicity of some herbal products [11, 12]. Pregnant and lactating women are especially prone to adverse effects from herbal medicines as the safety profiles and appropriate dosages of most of herbal medicines are not well studied in this group of populations [13].

In Ethiopia, more than $80 \%$ of the population use traditional medicine. A study done in Nekemte Hospital, Western Ethiopia showed that $69.8 \%$ of pregnant women use herbal medicines and the most common herbs used were ginger (44.4\%), garlic (37.3\%), and eucalyptus (9.1\%) [14]. Traditional medicine including the use of herbal medicines in Ethiopia is not only common but also culturally acknowledged. Yet there is scarcity of data on the prevalence and correlates of herbal medicine use among pregnant women. The present study aimed, therefore, to investigate the prevalence and correlates of herbal medicine use among pregnant women on ANC followup at Gondar university referral hospital, Ethiopia

\section{Methods}

\section{Study design and setting}

An institutional-based cross sectional study was conducted on 364 pregnant women attending ANC clinic from March 1 to May 28, 2016 at University of Gondar Referral and Teaching Hospital (UOGRTH), northwest Ethiopia. UOGRTH is located in Gondar town, northwest Ethiopia, $738 \mathrm{~km}$ away from Addis Ababa (the capital city of Ethiopia). The hospital is the only referral center in the area with multiple specialized clinics including ANC follow up clinic. Annually, more than 15,000 pregnant mothers visit the hospital for ANC services.

\section{Sample size determination and procedure}

Our source populations were all pregnant women attending ANC clinic of UOGRTH, while those pregnant women who visit the ANC clinic during the data collection period were taken as a study population. Single population proportion formula was used with the assumption of $95 \%$ confidence interval, $5 \%$ margin of error and $61.7 \%$ prevalence $[14,15]$ of herbal medicine use among pregnant women and $5 \%$ for possible nonresponse was taken to determine a final sample size of 410. According to GURH Statistics and Information Office record, an estimated number of 25 pregnant women visit the ANC clinic every day for ANC services. Thus, the total number of pregnant women who will visit the ANC clinic during the two month study period was calculated. The number of pregnant women to be interviewed per day during the 60 days of data collection was estimated to be 7 . By dividing the daily pregnant women visit with the number of pregnant women to be surveyed per day, every fourth pregnant women available at the ANC clinic during the two month data collection period were included by using systematic random sampling technique.

\section{Data collection method and survey instrument}

Data collection was performed by three graduating class pharmacy students through interviewer-administered questionnaire. The investigators were properly trained on the instrument and ways of approaching the patients and securing their permission for interview prior to the data collection process. The data collection tool was developed after a thorough literature review of the published studies [5, 6, 8-11] and prepared in English This was translated to local language (Amharic) and then back to English in order to ensure that the translated version gives the proper meaning. The data collection instrument was pretested on 20 pregnant women who were not included in the final analysis and relevant modifications were done before the commencement of actual data collection. The final questionnaire was constituting 
21 items that were divided into two main parts (Annex). The first section was focusing on the socio-demographic and pregnancy related information including age, marital status, educational level, history of ANC visit, current pregnancy status and duration of pregnancy. The second section aimed at assessing the level of herbal medicine use, information source about herbal medicine and discussion with physicians about herbal medicine use. The use of herbal medicine among respondents was assessed by a series of questions including use of herbal medicines during pregnancy, type of herbal medicine used, purpose of use, source of information and any untoward effects encountered while using herbal medicines. Respondents were labeled as herbal medicine users if they have taken herbal medicine(s) via any route of administration during gestational period. Routine meal preparations and those that are taken as nutrients (vitamin supplements) were excluded. The data collection tool along with a cover later is provided in Additional file 1.

\section{Statistical analysis}

The final data collection tool was checked for completeness, and responses were entered into and analyzed using the Statistical Package for the Social Sciences (SPSS) software version 21.0 for Windows. Frequencies and percentages were used to express different variables. Univariate analysis and multivariate logistic regression analysis were used to determine factors associated with herbal medicine use. The results were adjusted for patients' demographic and pregnancy related characteristics. Odds ratio (OR) with 95\% confidence interval (95\% CI) were also computed along with corresponding $p$-value $(p<0.05)$ as cut off points for determining statistical significance of associations among different variables.

\section{Results}

\section{Socio-demographic characteristics}

Out of 410 pregnant women invited to participate, 364 of them completed the survey giving a response rate of $88.8 \%$. The mean age of respondents was 26 years with a standard deviation of \pm 5.0 . Majority of the respondents were Orthodox Christians (87.6\%) and urban residents (79.7\%). About two-third (66.2\%) of the subjects drawn in this study were in their third trimester of pregnancy. The socio-demographic and pregnancy related characteristics of respondents are summarized in Table 1.

\section{Prevalence and indication of herbal medicine use}

Of the total respondents, 177 (48.6\%) used herbal medicine during current pregnancy, with two third of them (68.4\%) used during their third trimester. The most common herbal preparations used were ginger (Zingiber
Table 1 Socio demographic characteristics and factors associated with herbal medicine use among respondents, Gondar, $2016(N=364)$

\begin{tabular}{|c|c|c|c|c|}
\hline \multirow[t]{2}{*}{ Variables } & \multicolumn{4}{|c|}{ Herbal medicine use } \\
\hline & Yes (n) & No $(n)$ & $\operatorname{COR}(95 \% \mathrm{Cl})$ & $\operatorname{AOR}(95 \% \mathrm{Cl})$ \\
\hline \multicolumn{5}{|l|}{ Age group, in years } \\
\hline$<20$ & 29 & 20 & $\begin{array}{l}0.95 \\
(0.46-1.34)\end{array}$ & - \\
\hline $21-30$ & 122 & 116 & $\begin{array}{l}0.33 \\
(0.17-1.98)\end{array}$ & - \\
\hline$>30$ & 26 & 51 & 1 & - \\
\hline \multicolumn{5}{|l|}{ Residence } \\
\hline Rural & 48 & 26 & $\begin{array}{l}2.45 \\
(1.80-5.06)\end{array}$ & $\begin{array}{l}3.15 \\
(1.17-6.14)\end{array}$ \\
\hline Urban & 129 & 161 & 1 & 1 \\
\hline \multicolumn{5}{|l|}{ Educational status } \\
\hline Illiterate & 41 & 21 & $\begin{array}{l}3.14 \\
(1.94-5.78)\end{array}$ & $\begin{array}{l}4.05 \\
(2.48-6.62)\end{array}$ \\
\hline Primary & 40 & 33 & $\begin{array}{l}1.70 \\
(1.88-3.30)\end{array}$ & $\begin{array}{l}2.13 \\
(1.87-5.23)\end{array}$ \\
\hline Secondary & 65 & 60 & $\begin{array}{l}1.19 \\
(1.03-2.17)\end{array}$ & $\begin{array}{l}1.99 \\
(0.40-2.22)\end{array}$ \\
\hline Tertiary & 31 & 73 & 1 & 1 \\
\hline Religion & & & & - \\
\hline Orthodox Christian & 154 & 165 & 1 & - \\
\hline Muslim & 19 & 20 & $\begin{array}{l}0.91 \\
(0.85-0.97)\end{array}$ & - \\
\hline Others $^{a}$ & 4 & 2 & $\begin{array}{l}1.01 \\
(0.7-1.13)\end{array}$ & - \\
\hline \multicolumn{5}{|l|}{ Employment status } \\
\hline Government employed & 45 & 52 & $\begin{array}{l}0.83 \\
(0.42-1.64)\end{array}$ & $\begin{array}{l}0.57 \\
(0.24-1.34)\end{array}$ \\
\hline Self-employed & 19 & 34 & $\begin{array}{l}0.54 \\
(0.25-1.18)\end{array}$ & $\begin{array}{l}0.39 \\
(0.16-0.95)\end{array}$ \\
\hline Unemployed & 113 & 101 & 1 & 1 \\
\hline \multicolumn{5}{|c|}{ Average monthly family income } \\
\hline$<100$ & 133 & 105 & $\begin{array}{l}2.09 \\
(0.96-4.56)\end{array}$ & $\begin{array}{l}3.08 \\
(1.22-7.77)\end{array}$ \\
\hline $100-150$ & 35 & 38 & $\begin{array}{l}2.14 \\
(1.064-4.30)\end{array}$ & $\begin{array}{l}2.60 \\
(1.20-5.63)\end{array}$ \\
\hline$>150$ & 19 & 34 & 1 & 1 \\
\hline \multicolumn{5}{|l|}{ Presence of health problem } \\
\hline No & 47 & 165 & $\begin{array}{l}0.65 \\
(0.36-1.18)\end{array}$ & $\begin{array}{l}0.56 \\
(0.29-1.08)\end{array}$ \\
\hline Yes & 130 & 22 & 1 & 1 \\
\hline Parity & & & & - \\
\hline 1-2 children & 141 & 131 & $\begin{array}{l}0.69 \\
(0.31-1.53)\end{array}$ & - \\
\hline 3-4 children & 27 & 49 & $\begin{array}{l}0.89 \\
(0.41-1.93)\end{array}$ & - \\
\hline$>4$ children & 9 & 7 & 1 & - \\
\hline
\end{tabular}

Abbreviations: AOR Adjusted odds ratio; COR: Crude odds ratio

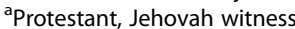


officinale) (40.7\%) and damakasse (Ocimum lamiifolium) (38.4\%) The most common indications for use were common cold (66\%), and inflammation (31.6\%). Herbal preparations used and their indications are summarized in Figs. 1 and 2.

Table 2 describes the characteristics of herbal medicine use among respondents. The most commonly cited source of information about herbal medicine was families, relatives and friends (46.9\%) followed by other pregnant women who used herbal medicines (36.1\%). The most commonly stated reason for using herbal medicine was "herbal medicines are cheap and accessible (54.8\%)", followed by "safe in pregnancy (18.6\%)". Similarly, the most common reason for not using herbal medicine among non-users was "lack of belief in the benefits of herbs (45.4\%) followed by "afraid the side effect $(31 \%)$ ". The majority of pregnant women who use herbal medicines $(89.8 \%)$ did not discuss their use of herbal medicines with health care practitioners. Most of herbal medicine users (87.6\%) reported that they haven't experienced any apparent side effects from herbs. However, only $31.1 \%$ of the respondents answered that they were satisfied with the result of herbal medicine use.

\section{Factors associated with herbal medicine use}

Variables that were significantly associated with herbal medicine use in the bivariate analysis were further examined in multivariate logistic regression. Accordingly, residence, educational status and average monthly income were found to have a significant association in multivariate logistic regression analysis. The odds of herbal medicine use during pregnancy was 3.15 times higher among rural residents as compared to urban residents (AOR: 3.15, 95\% CI: 1.17-6.14). Pregnant women who were illiterate (no formal education) were 4.05 times more likely to use herbal medicine than those who attended tertiary education (AOR: 4.05CI: 2.48-6.62). It also showed that pregnant women who had average monthly income less than 100 USD were 3.08 times more likely to use herbal medicine than those who had average monthly income of greater than 200USD(AOR: 3.08CI: 1.22-7.77). There is no significant association between herbal medication use and age group, religion, education status, parity, previous ANC follow up or duration of pregnancy both in the bi-variate and multivariate logistic regression analysis (Table 1 ).

\section{Discussion}

Currently, the use of herbal medicine is a common practice both in developed and developing country [16]. The present study aimed to assess the prevalence and correlates of herbal medicine use among pregnant women attending ANC clinic at University of Gondar referral and teaching hospital, northwest Ethiopia. According to the finding of our study, $48.6 \%$ used herbal medicine during current pregnancy, with two thirds (68.4\%) reporting use during the third trimester. This finding is comparable with reports from western Ethiopia (50.4\%) [14] and in Malaysia (51.4\%) [16]. However, it was higher compared to findings from Kenya 12\% [11], and Italy (27.8\%) [17] and lower than a report from Southern Ethiopia [15]. The difference in prevalence may be due to variation in accessibility, affordability and cultural issues regarding herbal and modern medicine use between nations and districts of a country. The common practice of herbal medicine use in our study could be partially explained by the fact that the tradition and culture in Ethiopia encourages the use of herbal medicines, which is further

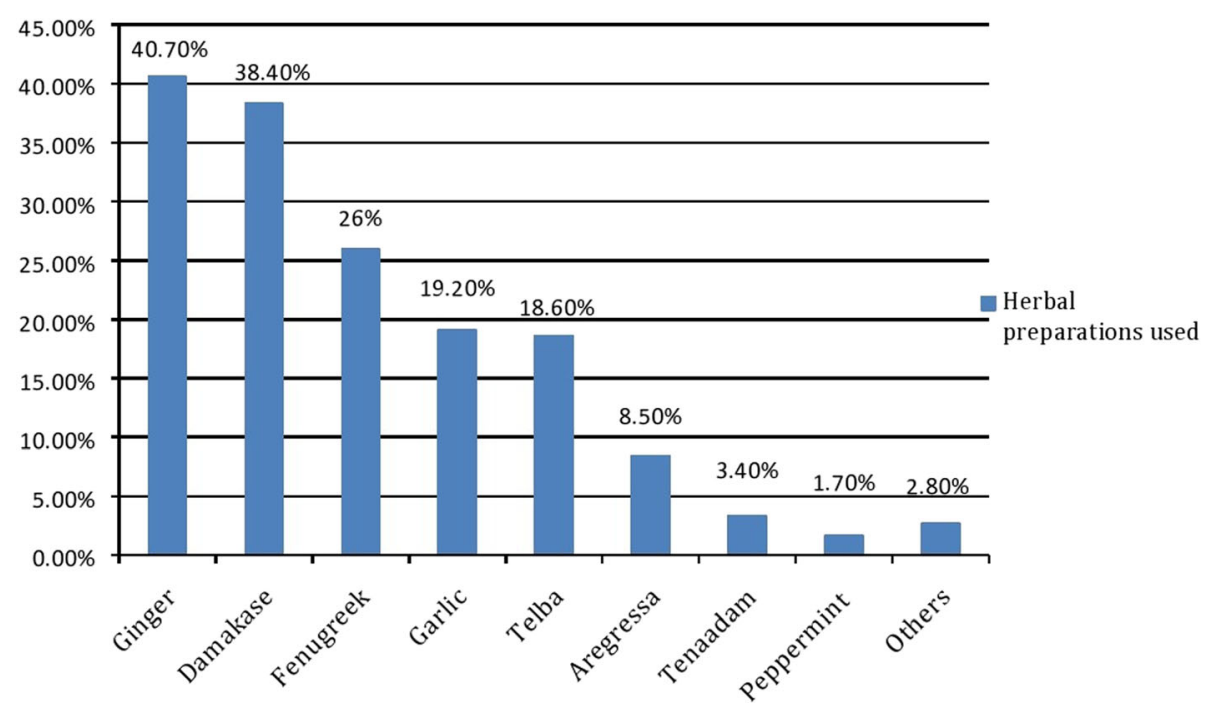

Fig. 1 Herbal preparations used during current pregnancy, Gondar, 2016 


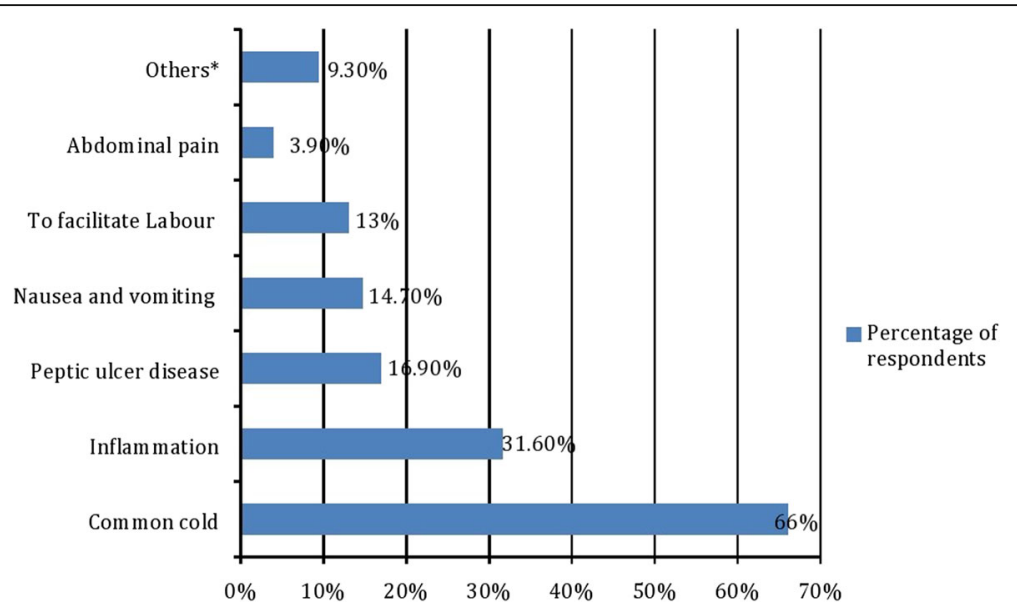

Fig. 2 Indications for herbal medicine use during pregnancy, Gondar, 2016

augmented by the presence of many traditional medicine practitioners.

In our study, ginger (40.7\%) is the most commonly used herbal medicines during pregnancy. Similarly, a study done in Alexandria revealed that ginger (52.4\%) is the most commonly used herb in pregnant women [18]. However, in the study conducted in Virginia, peppermint (18\%) was the most commonly used herb [19]. Other common herbal preparations reported in our study were fenugreek (26\%), garlic (19.2\%), telba (18.64\%), aregressa (5.65\%) and tenaadam (3.4\%). The difference in pattern across different regions may be due to difference in accessibility and geographical distribution of herbs. However, the pattern of herbal medicine use in our study is almost similar to the study done in Hosanna town, southern Ethiopia where garlic, ginger, tenaadam and damakasse were reported to be the commonest herbs used by pregnant women [15]. Unlike the finding of this study, the common indications of herbal remedies were for labor facilitation (89.8\%) followed by morning sickness (21\%) in Malaysia [16] and for diarrhea (39.4\%) and diabetes (31.6\%) in Nigeria.

This indicates the presence of multiple claimed therapeutic roles of herbal preparations during gestational period which may need scientific clarification.

To prevent the possible harm imposed by the use of herbal medicines, health care providers should emphasize safety issues to pregnant women and make an effort to endow women with evidence-based information regarding herbal medicines. In our study, herbal medicine use was discussed with their health care providers by only $10.2 \%$ of pregnant women. The lack of communication between the health care providers and pregnant woman who are using herbal medicine may have a harmful effect on the mother as well as the fetus i.e. teratogenicity. Therefore, health care providers should acknowledge women's' use of herbal medicine, encouraging active conversation for the proper use of herbal medicines. The most common reasons cited for not using herbal medicines among non-users were lack of belief in the benefits of herbs (45.4\%) followed by fear of side effects (31\%). This finding corroborates the finding of the study conducted in Alexandria, where $44.5 \%$ of women do not trust in the benefits of herbs [18]. However, the Nigerian study reported that $33.4 \%$ of respondents trust in the benefits of herbs and 30.4\% respondents believe that herbal medicines do not have adverse effects [6]. This may be due to socio-cultural difference among the respondents in study areas.

The odds of herbal medicine use during pregnancy were 3.15 times higher among rural residents as compared to urban residents. This may be due to difference in the accessibility of conventional medicine and health care center in rural and urban area. Pregnant women who were illiterate (no formal education) were 4.05 times more likely to use herbal medicine than those who attended tertiary education. This finding was in line with the study conducted in Hossana, Ethiopia, Nigeria [6, 20], Kenya [11], Nekemte [14] and Ghana [21]. It also showed that pregnant women who had average monthly income less than 100 USD were 3.1 times more likely to use herbal medicine than those who had average monthly income of greater than 200USD. This is similar with the study done in Malaysia [16]. This phenomenon might be explained by low cost of the traditional medicine compared to the modern medicine services [14].

\section{Limitations of the study}

The study has some limitations that should be taken into account while interpreting the results. As the study is cross sectional and depends on self-reported assessment, 
Table 2 Characteristics of herbal medicine use among respondents, Gondar, $2016(N=364)$

\begin{tabular}{ll}
\hline Variables & Frequency, \\
\hline Herbal medicine use during current pregnancy & \\
No & $187(51.4)$ \\
Yes & $177(48.6)$ \\
Source of information about herbal medicine ${ }^{a}(n=177)$ & $83(46.9)$ \\
Families, friends and relatives & $4(2.2)$ \\
Health care professionals & $26(14.7)$ \\
Media (internet, television, radio, book) & $64(36.1)$ \\
Pregnant women who used herbal medicines & \\
Reasons for herbal medicine use ${ }^{\text {a }}(n=177)$ & $22(12.4)$ \\
Family, tradition or culture & $25(14.2)$ \\
Belief in effectiveness of herbal medicines & $97(54.8)$ \\
Herbal medicines are cheap and accessible & $13(7.3)$ \\
Treatment of other medical problems & $33(18.6)$ \\
Safe in pregnancy &
\end{tabular}

Reason for not using herbal medicines among non-users $(n=187)$

Lack of belief in the benefits of herbs

$85(45.4)$

Afraid the side effect

$58(31)$

Lack of availability

Didn't get sick during gestation

Discuss with HCPs about herbal medicine use $(n=177)$

No

$159(89.8)$

Yes

Side effects from herbal medicine use $(n=177)$

$\begin{array}{ll}\text { No } & 155(87.6) \\ \text { Yes } & 22(12.4) \\ \text { Satisfaction with herbal medicine use }(n=177) & \\ \text { Satisfied } & 55(31.1) \\ \text { Average } & 74(41.8) \\ \text { Dissatisfied } & 48(27.1)\end{array}$

Abbreviation: HCPs Health care practitioners

${ }^{a}$ More than one option possible

under reporting is very likely. Thus, an exact cause and effect associations here in this study is difficult.

\section{Conclusion}

The use of herbal medicine during pregnancy is a common practice and associated with rural residency, illiteracy and low average monthly income. Pregnant women depend mainly on family, friends and relatives as a source of information about herbal medicines. Commonly used herbs among pregnant women were ginger (Zingiber officinale) and damakasse (Ocimum lamiifolium) and the most common indication for use were common cold and inflammation. Given the high frequency of herbal medicine and a very low disclosure rate, health care providers should be open to discuss the use of herbal medicines with their pregnant women as it will lead to better health outcome. It is also recommended that commonly used herbal preparations should be further studied to certify their efficacy and safety.

\section{Additional file}

Additional file 1: Questionnaire used for the study. (DOCX 28 kb)

\section{Abbreviations}

ANC: Anti natal care; AOR: Adjusted odds ratio; Cl: Confidence interval; OR: Odds ratio; SPSS: Statistical Package for the Social Sciences;

UOGRTH: University of Gondar Referral and Teaching Hospital; USD: United

States dollar; WHO: World Health Organization

\section{Acknowledgements}

The author acknowledges the support of the school of Pharmacy, University of Gondar and ANC clinic of UOGRTH in facilitating the data collection process.

\section{Funding}

No financial support was gained to conduct the study.

\section{Availability of data and materials}

The materials and data of this study are available from the corresponding author upon request.

\section{Authors' contributions}

All authors involved in the conceptualization of the study, data collection supervision and write up of the first draft of the manuscript as well as submission of the manuscript. All authors read and approved the final manuscript.

\section{Competing interests}

The authors declare that they have no competing interests.

\section{Consent for publication}

Not applicable.

\section{Ethics approval and consent to participate}

This study was approved by the ethical committee of University of Gondar with an approval number of UoG-586/2016. Informed consent from the respondents was also obtained before conducting this study. Participants' information obtained was kept confidential.

\section{Author details}

${ }^{1}$ Department of Pharmacology, College of Medicine and Health Sciences, University of Gondar, Chechela Street, Lideta Subcity Kebele 16, Gondar, Ethiopia. ${ }^{2}$ Department of Pharmacy Practice, School of Pharmacy, University of Gondar, Gondar, Ethiopia. ${ }^{3}$ Department of Pharmacognosy, School of Pharmacy, University of Gondar, Gondar, Ethiopia. ${ }^{4}$ Department of Pharmacology, School of Pharmacy, University of Gondar, P.O. Box: 196, Gondar, Ethiopia.

Received: 20 June 2016 Accepted: 27 January 2017

Published online: 01 February 2017

\section{References}

1. World health organization. Legal status of traditional medicine and complementary/alternative medicine: a world wide review. Geneva: WHO; 2001.

2. Ernst E. Herbal medicines put into context. Br Med J. 2003;327(7420):881-2.

3. Furnharm A. Why do people choose and use complementary therapies? In Complementary medicine an objective Appraisal Edited by: Ernst E. Oxford: Butterworth-Heinemann; 1996.

4. World Health Organization. Traditional medicine. Fact sheet Number 134. http:// www.who.int/mediacentre/factsheets/2003/fs134/en/. Accessed 2 Feb 2015. 
5. Henry $A B$, Crowther $C A$. Patterns of medication use during and prior to pregnancy: the MAP study. Aust N Z J Obstet Gynaecol. 2000;40:165-72.

6. Titilayo OF, Rasaq AD, Ismail EM. Attitude and use of herbal medicines among pregnant women in Nigeria. BMC Complement Altern Med. 2009;9:53. doi:10.1186/1472-6882-9-53.

7. Paula Gardiner PA, Kemper JK, Legedza AA, Phillips RS. Factors associated with herbal therapy use by adults in the United States. BMC Complement Altern Med. 2007;7:39.

8. Fakeye TO, Adisa R, Musa IE. Attitude and use of herbal medicines among pregnant women in Nigeria. BMC Complement Altern Med. 2009;9:53.

9. Ernst E. Herbal medicinal products during pregnancy: are they safe? BJOG. 2002;109:227-23

10. Forster DA, Denning A, Wills G, Bolger M, McCarthy E. Herbal medicine use during pregnancy in a group of Australian women. BMC Pregnancy Childbirth. 2006;6:21.

11. Mothupi MC. Use of herbal medicine during pregnancy among women with access to public healthcare in Nairobi, Kenya: a cross-sectional survey. BMC Complement Altern Med. 2014;14:432. doi:10.1186/1472-6882-14-432.

12. Dugoua JJ, Perri D, Seely D, Mills E, Koren G. Safety and efficacy of blue cohosh (Caulophyllum thalictroides) during pregnancy and lactation. Can $」$ Clin Pharmacol. 2008;15(1):66-73.

13. Conover EA. Herbal agents and over the counter medications in pregnancy: best practice \& research. Clin Endocr Met. 2003;17(2):237-51.

14. Bayisa B, Tatiparthi R, Mulisa E. Use of herbal medicine among pregnant women on antenatal care at Nekemte Hospital, Western Ethiopia. Nat Pharm Prod. 2014:9(4):e17368.

15. Tariku LO, Tadele YS, Fiseha LO. Prevalence of herbal medicine use and associated factors among pregnant women attending antenatal care at public health facilities in Hossana Town, Southern Ethiopia. Arch Public Health. 2016;74:7.

16. Ab A, Sulaiman AS, Ahmad ZF, Daud NW, Hamid AM. Prevalence and pattern of use of herbal medicines during pregnancy in Tumpat district, kelantan, Malaysia. Malays J Med Sci. 2008;15(3):40-8.

17. Laura C, Francesco F, Giovani V, Marco J, Paolo B, Giuseppina B. Use of herbal products among 392 Italian pregnant women: focus on pregnancy outcome. PharmacoEpidemiol Drug Saf. 2010;19(11):1151-8.

18. Yasser IO, Nadia FF, Mohamed IA. Use of herbal medicines among pregnant women attending family health centers in Alexandria. Middle East Fertil Soc J. 2014:19:42-50.

19. Glover DD, Amonkar MS, Rybeck BF, Tracy TS. Prescription over-the-counter and herbal medicine use in a rural, obstetric population in west Virginal. Am J Obstet Gynecol. 2003;188:1039-45.

20. Bello UL, Isah JN. Use of herbal medicines and aphrodisiac substances among women in Kano state, Nigeria. IOSR J Nursing Health Sci. 2015;4(3):41-50.

21. Addo VN. Herbal medicines: socio-demographic characteristics and pattern of use by patients in a tertiary obstetrics and gynaecology unit. J Sci Technol. 2007:27(3):149-60.

\section{Submit your next manuscript to BioMed Central and we will help you at every step:}

- We accept pre-submission inquiries

- Our selector tool helps you to find the most relevant journal

- We provide round the clock customer support

- Convenient online submission

- Thorough peer review

- Inclusion in PubMed and all major indexing services

- Maximum visibility for your research

Submit your manuscript at www.biomedcentral.com/submit

CBiomed Central 